\title{
Global scepticism, underdetermination and metaphysical possibility
}

\author{
Luca Moretti \\ Aberdeen University \\ 1.moretti@abdn.ac.uk
}

\begin{abstract}
I focus on a key argument for global external world scepticism resting on the underdetermination thesis: the argument according to which we cannot know any proposition about our physical environment because sense evidence for it equally justifies some sceptical alternative (e.g. the Cartesian demon conjecture). I contend that the underdetermination argument can go through only if the controversial thesis that conceivability is per se a source of evidence for metaphysical possibility is true. I also suggest a reason to doubt that conceivability is per se a source of evidence for metaphysical possibility, and thus to doubt the underdetermination argument.
\end{abstract}

\section{Introduction}

In this paper I focus on the underdetermination argument (hereafter UA) for global external world scepticism according to which we cannot know any contingent proposition $h$ about our environment because any sensory evidence for $h$ equally justifies some sceptical scenario $s h$ alternative to $h$ (e.g. the Cartesian demon scenario or the brain-in-a-vat scenario). My central claim is conditional. I contend that the UA can succeed only if the following controversial thesis is true: one's mere conceiving of or imagining some sate of affairs $p$ can give one some degree of justification for believing that $p$ is metaphysically possible. In short, I argue that since degrees of justification are closed under known entailment, sensory evidence can provide no degree of justification for a proposition $p$ if there is no degree of justification for its known consequence $\diamond p$, i.e. the claim that $p$ is metaphysically possible. I then contend that if $p$ is an ordinary hypothesis about our environment, perceptual justification available for $p$ is often able to transmit to its consequence $\diamond p$. However, if $p$ is a sceptical scenario, no 
degree of empirical justification for $p$ could transmit to $\diamond p$. Thus, if no faculty a priori such as conceivability, imagination, or intuition is a source of evidence for metaphysical possibility, sensory evidence will favour ordinary world hypotheses over their sceptical alternatives, to the effect that the UA fails. I finally suggest reasons for doubting that conceivability is per se guide to metaphysical possibility, and thus to doubt the UA.

This is the structure of the paper: $\S 2$ introduces the UA. $\S 3$ introduces my novel line of reply to it. $\S 4$ introduces preliminary notions. $\S 5$ argues that sense experience gives us prima facie immediate justification for taking the contents of our experiences to be both true and metaphysically possible. $\S 6$ argues that sensory evidence can give us no degree of justification for taking any sceptical alternative to any ordinary world hypothesis to be true if we have no degree of independent justification for considering the sceptical alternative to be metaphysically possible. $\S 7$ conclude that if conceivability per se is no source of evidence for metaphysical possibility, our experiences will favour ordinary world hypotheses over their sceptical alternatives. $\S 8$ sheds doubts on the thesis that conceivability is inherently a source of evidence for metaphysical possibility. $§ 9$ draws the conclusions.

\section{Global external world scepticism and the UA}

Consider any ordinary world hypothesis $h-$ i.e. any proposition $h$ that supposedly describes contingent facts in our putative environment. A sceptical alternative sh to $h$ - or sceptical scenario - is a situation subjectively indistinguishable from one in which we would ordinarily assume that we know $h$, but in which we don't know $h$. Additionally, a sceptical alternative is a situation in which we couldn't possibly discover we are mistaken or deceived, no matter how much or how deep we might investigate 
(cf. Klein 2008: §1). By adducing the possible instantiation of scenarios of this type, the global sceptic argues that the knowledge of the external world is for us impossible.

Suppose for instance $h$ is the proposition that I'm writing this paper now. Circumstances in which I would assume that I know that I'm writing this paper now are those in which I have the vivid experience as if I'm writing this paper now. A sceptical alternative $s h$ to $h$ is the Cartesian conjecture that I'm a disembodied soul in an immaterial world with the mere hallucination of writing this paper caused by a vicious demon. A modern version of this conjecture is the brain-in-a-vat scenario, according to which I'm nothing but a vatted brain having the hallucination of writing this paper generated by a computer connected to my neurons. In either case if $s h$ is true I'm not writing this paper now, thus I cannot know it. ${ }^{1}$ In either case the deception wouldn't be detectable by me because the demon and the computer are deemed to give me the perfect illusion of the whole world coherent with my experience as if I'm writing this paper now. ${ }^{2}$ Since any ordinary world hypothesis $h$ possesses sceptical alternatives like $s h$, the sceptic thinks she can conclude that knowing any $h$ is just impossible for us.

Note that conjectures that ascribe to us ordinary (or more ordinary) deceptive experiences - e.g. the conjecture that we are simply dreaming and the one that we have been given hallucinogenic drugs -

\footnotetext{
${ }^{1}$ In both examples $s h$ and $h$ are incompatible, but this is not necessary. It might be that $h$ is true but I don't know it because a Gettier sceptical scenario sh obtains. As the UA is standardly formulated assuming that $s h$ and $h$ are incompatible, I will not consider Gettier alternatives. My response could however be reformulated to comprehend Gettier scenarios. For sensory evidence doesn't seem to supply evidence that $\nabla$ sh even if $s h$ is a Gettier scenario.

${ }^{2}$ In both examples, sh is an all-encompassing conjecture, but this is not necessary. Consider for instance the local sceptical alternative that a vicious demon has hallucinated me just now by making me believe that I'm writing this paper now and that it will intervene again only if I'm close to detect that my experience was illusory. Global scepticism could be defended by arguing that we may fall victim to a combined action of local sceptical scenarios of this type.
} 
don't seem to qualify as genuine sceptical alternatives. For conjectures of this type can foster only ordinary incredulity but not philosophical scepticism - the position that knowledge is impossible (cf. Klein 2008: §1). ${ }^{3}$ A sceptical alternative is one in which we couldn’t detect that we are mistaken or deceived. Dreams and drugs-induced hallucinations do not satisfy this requirement, as we can normally acquire evidence that we had deceptive experiences of this type. For example, dreams and drugsinduced hallucinations last for a (relatively) short time and are typically inconsistent or discontinuous with the rest of our experience. We can normally establish that we have been victim of hallucinations or that we had a dream by contrasting our experiences with other people's experiences, or by checking the consequences of the allegedly perceived events. We can find out that we have been given hallucinogenic drugs by testing our blood, and so on. ${ }^{4}$

The global sceptic may use different arguments to support her view: one very much discussed today is the UA (cf. Pritchard 2005b, Vogel 2004, Brueckner 1994 and Yalçin 1992). In the current debate the UA is perhaps surpassed in popularity only by arguments relying on the principle of closure under entailment for knowledge. Despite this, the UA looks more insidious than the closure arguments. For the UA doesn't seem to presuppose the principle of closure for knowledge, which some philosophers prominently Dretske and Nozick - contend we should drop (cf. Pritchard 2005b).

\footnotetext{
${ }^{3}$ Descartes notoriously made use of the dreaming hypothesis, but this appears to be a propaedeutic means for him to reach a proper sceptical scenario (cf. for instance Owens 2000).

${ }^{4}$ The dreaming conjecture can be turned into a genuine sceptical alternative by suitable alterations. For example, the conjecture that my lifelong experience is just a coherent dream is a sceptical alternative. Note that the question whether this bizarre hypothesis is metaphysically possible can be raised in full force. If this scenario is used in the UA, then the arguments of this paper apply to it. It is more difficult to understand if the drugs-induced hallucination conjecture can be turned into a genuine sceptical alternative. I suspect that if it does, it becomes similar to the brain-in-a vat scenario, which I discuss below. Then the same general objections apply.
} 
The UA makes use of the plausible thesis that if experience doesn't justify a proposition $h$ more than an incompatible rival, it cannot justify belief in $h$. When used to defend global external world scepticism, the UA applies to any ordinary world hypothesis $h$ apparently supported by some sensory evidence. Suppose $S$ is a rational subject. This is a seemingly operational version of UA:

(1) For any ordinary world hypothesis $h, S$ 's sensory evidence cannot justify $S$ 's belief in $h$ more than $S$ 's belief in any sceptical alternative $s h$ conceivable by $S$.

(2) But $S$ could be justified to believe $h$ by her sensory evidence only if this evidence justified $h$ more than any sceptical alternative $s h$ conceivable by $S$.

(3) Therefore, $S$ cannot be justified to believe $h$ by her sensory evidence.

(4) But $S$ could be justified to believe $h$ only by her sensory evidence.

(5) Therefore, $S$ cannot be justified to believe $h$.

(6) But $S$ could know $h$ only if $S$ were justified to believe $h$.

(7) Therefore, for any ordinary world hypothesis $h, S$ cannot know $h$.

I consider possible lines of attack against the UA in the next section. An important preliminary question is how to interpret the expression 'sensory evidence' in the UA. I interpret 'sensory evidence' (and 'experience') in a disjunctive fashion - namely, as referring indifferently to $S$ 's sense experience as if some state of affairs in the external world is the case or $S$ 's introspective experience as if she is having the sense experience as if some state of affairs in the external world is the case. Thus ' $S$ 's sensory evidence' (and ' $S$ 's experience') can indifferently refer to, say, $S$ 's experience as if there is an apple here or $S$ 's introspective experience as if she is having the sense experience as if there is an apple here. I will suggest in the next sections that while many ordinary world hypotheses can directly be supported by sense experiences, sceptical alternatives can only be supported by introspective experiences.

Let me now clarify the notion of sense experience I will be presupposing. I follow many extant epistemologists and philosophers of mind in assuming that our sense experiences (at least many of 
them) are not mere occurrences of sense data but mental states provided with contents (cf. Pryor 2000, Huemer 2001, and Siegel and Silins 2013). ${ }^{5}$ These contents are about observable states of affairs in the external world. Experiences and beliefs have it in common that they both represent assertively: when they represent a given content, they do so in a way that purports to show how the world actually is. ${ }^{6}$ Thus both experiences and beliefs have conditions of truth or accuracy. Experiences and beliefs differ, however, because of the distinctive ways in which the experiencer and the believer entertain a same content $p$ : whereas the first experiences as if $p$, the second believes that $p .^{7}$ I will follow many philosophers of perception and epistemologists in assuming that simple middle-sized objects, such as faces, apples and hands - or at least their basic properties, like their shape, color, consistency and location - can genuinely be represented by our sense experiences. (For a survey of the different positions see Siegel 2011).

\section{My new line of reply to the UA}

Although the UA appears logically valid, its premises could be attacked from different sides. For example, reliabilists about epistemic justification would deny that justification is solely a matter of having suitable experience. They could try to reject (1) by claiming that whether or not $S$ 's belief $h$ is justified when $S$ 's has a suitable experience essentially depends on whether or not the belief formation

\footnotetext{
${ }^{5}$ Some philosophers distinguish representational contents form propositional contents. For simplicity I will follow Pryor in taking experiences to have propositional content. Nothing substantive rests on this assumption. It seems to me that my arguments could be reformulated, without drastic changes, by assuming that experiences have richer representational contents.

${ }^{6}$ Note that other mental states provided with content - e.g. doubting and hoping - do not represent their content assertively.

${ }^{7}$ We may experience a given content without believing it. This seems to happen in optical illusions.
} 
process used by $S$ is reliable, which is a matter of fact that cannot be decided a priori by a thought experiment. I'm not satisfied with this response. Process reliabilism is affected by gruelling problems such as the generality and the bootstrapping one (cf. Goldman 2011: §3). Independently of this, I doubt that a reliabilist response would be appropriate because reliabilism presupposes epistemic externalism. I tend to believe that when epistemological scepticism is the subject of discussion, the underlying notion of justification is internalist. Hence any externalist response to scepticism would probably be inadequate. $^{8}$

Abductivists could attempt to reject (4) contending that $S$ has non-empirical evidence - in particular, explanatory evidence - that favours $h$ over any suitable sceptical alternative. Suppose $S$ experiences as if $h$. The fact that $S$ has this experience can apparently be explained in at least two ways: by the conjunctive hypothesis that $h$ is the case and $S$ veridically perceives that $h$, or by a suitable sceptical scenario sh. Abductivists could argue that since the first hypothesis gives the best potential explanation of $S$ 's experience, $S$ is justified to believe it - and so $h$ - over any sh (cf. Bonjour 2003, Vogel 1990 and Moser 1989). For an overview of the difficulties that swamp antisceptical responses of this type see however Lycan (2002), Douven (2011) and, more specifically, Beebe (2009). To begin with, the claim that sceptical scenarios cannot constitute the best potential explanations of our experiences has been questioned (see for instance Feldman 2003: 150). More generally van Fraassen (1980) has argued that the notion of explanation is interest-, context- and subject-relative in a number of ways that don't apply to the notion of epistemic justification. Thus it is implausible that explanatory force can generally

\footnotetext{
${ }^{8}$ Proper function, agent and virtue reliabilists could raise more sophisticated objections to the UA that would still presuppose externalism about justification.
} 
produce epistemic justification. One could convincingly claim that explanatory force produces epistemic justification (at least in some cases) if one were able to substantiate the thesis that explanatory force (in those cases) is truth-conducive. But this looks like a formidable task. A priori defences of this thesis appear implausible. For it is implausible that there exists a necessary link knowable a priori between explanatory force and objective truth. A posteriori defences typically rely on abductive arguments, so they seem to presuppose the truth of the very thesis that explanatory force is truth-conducive and look suspiciously circular. In conclusion the responses to the UA that appeal to evidential consequences of explanatory force have a little chance to succeed.

Truth-tracking reliabilists about knowledge who contend that justification is no essential component of knowledge could try to reject (6). But I follow the wide majority in epistemology in considering (6) plausible. Furthermore, if (6) were dropped, the UA could still hit our pretences to epistemic justification, which would be bad enough. Thus I will not pursue this line of reply. Perhaps advocates of entitlement theories - like Wright (2004) - could attempt to defuse the UA in a way or another. I'm not interested in exploring this possibility because entitlement theories - especially Wright's - are quite controversial. $^{9}$

As I'm dissatisfied with traditional responses to the UA, I would like to explore a novel line of reply that targets (1). A sceptical scenario is a situation that we know or have some evidence to believe that it is possible, but in what sense of possible? A widespread assumption in the literature is that a sceptical scenario should be metaphysically possible - i.e. a way the world could be - rather than, for example,

\footnotetext{
${ }^{9}$ A major difficulty is that the notion of entitlement would seem to be pragmatic in nature rather than epistemic (cf. Pritchard 2005a and Jenkins 2007).
} 
one just logically, conceptually, epistemically or a priori possible (cf. Graham 2008 and 2007, Bonjour 2002, Pryor 2000 and Levin 2000). Kung (2011: 2-5) defends this shared assumption by contending that we need not be concerned about cognitive errors engendered by a scenario if we have no reason for believing that the scenario corresponds to a way the world could be. In other words, an imagined situation that we have no reason to believe to be capable of actualising can pose no genuine threat to our pretences to knowledge.

It is hard to ascertain whether or not Kung's thesis is generally true - i.e. whether any possible sceptical argument does require justification for believing that the sceptical scenarios adduced in it are metaphysically possible. ${ }^{10}$ It appears to me that Kung's thesis is true at least when applied to the UA. For, whenever $h$ stands for a content of $S$ 's sense experience, premise (1) of the UA proves false if $S$ has no degree of justification for believing that the sceptical alternatives $s h s$ to $h$ are metaphysically possible. I argue below that if $h$ is a content of $S$ 's experience, $S$ 's sensory evidence can give $S$ prima facie justification for believing $h$ even if $S$ has no degree of independent justification for believing $\nabla h$.

${ }^{10}$ Beebe (2010: §IV) contends that this general claim is false. Consider for instance Descartes' conjecture, in his first Meditation, that an omnipotent being might be deceiving us about elementary mathematical propositions that we seem to grasp by reason alone. Suppose $s h=$ 'It is false that $2+3=$ 5 but the omnipotent being makes me believe that $2+3=5$ '. Consider the following argument:

(i) If I know that $2+3=5$, then I know that $\sim s h$.

(ii) I don't know that $\sim s h$.

(iii) Therefore, I don't know that $2+3=5$.

This argument is valid. Premise (i) is true, and Beebe (2010: 460-461) claims that (ii) is prima facie plausible. Beebe emphasises that we have no evidence for believing that $s h$ is metaphysically possible - quite the opposite, we seem to have a priori justification for believing that sh is metaphysically impossible. Nevertheless $s h$ does threat our mathematical knowledge. There are perhaps ways to resist Beebe's claims that I cannot survey here (see however Kung 2009). At any rate, what Beebe seems to have shown is only that some sceptical arguments don't need justification for believing that the sceptical alternatives adduced in them are metaphysically possible. Note that these arguments are not versions or instances of the UA. 
My argument rests on a popular conception of perceptual justification according to which experiences immediately justify their contents. I also argue that the same sensory evidence can give $S$ no degree of justification for believing any sceptical alternative $s h$ to $h$ if $S$ has no degree of independent justification for believing $\diamond$ sh. Underdetermination between a content $h$ of $S$ 's sense experience and its sceptical alternative shs can thus arise only if $S$ has some degree of independent justification for believing that these shs are metaphysically possible. If $S$ has no degree of justification for believing so, $S$ 's sensory evidence will give $S$ some justification for $h$ but no justification for any alternative $s h$. This falsifies (1).

My ideal goal would be to show that (1) is just false because, when $h$ stands for a content of $S$ 's sense experience, $S$ can have no degree of justification for $\diamond s h$, where $s h$ is any sceptical alternative to $h$. To keep my paper manageable, I will content myself with showing that (1) is questionable because, when $h$ stands for a content of $S$ 's sense experience, $S$ can have no degree of empirical justification for $\vartheta_{s h}$, where $s h$ is any sceptical alternative to $h$. Thus (1) must rest on the controversial thesis that conceivability, or a similar faculty a priori, is per se a source of evidence for metaphysical possibility. Should this controversial thesis fall, the UA will fall together with it. This upshot suffices - hopefully to shed substantive doubts on the soundness of this important sceptical argument.

Many philosophers nowadays distinguish between two types of antisceptical projects (cf. Huemer 2000, Pryor 2000 and Vogel 2005). The first type of project is quite ambitious: refuting the sceptic on her own terms - that is, proving that we have the knowledge or justification we think we have by using only premises that the sceptic permits us to accept. The chance of success of projects of this sort is clearly very slight. The second type of antisceptical project is more modest: refuting the sceptic by our 
own standards. In this case the sceptic is thought of as presenting us with arguments from premises that we find intuitively plausible to the conclusion that we cannot know or justifiably believe anything. Our more modest antisceptical task consists in attempting to defuse these arguments while retaining as many as possible of the premises that we find intuitively plausible. The response to the UA that I put forward in this paper is in line with this second type of antisceptical project.

\section{Transmission and transmission failure of degrees of justification}

In the next sections I will make use of variants of Wright (2002)'s notions of transmission and transmission failure of justification across entailment. ${ }^{11}$ I would like to introduce these notions here. Let's start with Wright's accounts. Consider evidence $x^{12}$ and propositions $y$ and $z$, where $y$ entails $z$. We can say the justification from $x$ for $y$ transmits to $z$ across the entailment just in case the following conditional is non-vacuously true:

If a subject $S$ acquires from $x$ justification sufficient for believing $y$ and deduces $z$ from $y, S$ thereby acquires for the first time justification sufficient for believing $z$.

Although justification is presumably closed under known entailment, ${ }^{13}$ justification doesn't always transmit across known entailment. We have a trivial case of transmission failure when no justification from $x$ for $y$ transmits to $z$ across the entailment because the above conditional is vacuously true. We have a non-trivial case of transmission failure when no justification from $x$ for $y$ transmits to $z$ across

${ }^{11}$ I will only focus on transmission and transmission failure of first time justification. See Moretti and Piazza (2013) for more comprehensive accounts.

${ }_{12}^{12}$ For our purposes it is indifferent whether $x$ is a belief or an experience.

${ }^{13}$ In the sense that, roughly, if $S$ has justification sufficient for believing $y$ and knows that $y$ entails $z, S$ has justification sufficient for believing $z$. 
the entailment because the above conditional is false. Wright has put forward the following condition whose satisfaction suffices for transmission failure:

The justification from $x$ for $y$ is conditional on independent justification for $z$ (i.e. $x$ could give $S$ justification sufficient for believing $y$ only if $S$ had independent justification sufficient for believing $z$ ).

Suppose this condition is satisfied. If $S$ is not independently justified to believe $z, S$ will not acquire from $x$ justification sufficient for believing for $y$ in the first instance. This is a trivial case of transmission failure because there is simply no justification to be transmitted to $z$. On the other hand, if $S$ is independently justified to believe $z, S$ will acquire from $x$ justification sufficient for believing $y$, but $S$ will not acquire justification sufficient for believing $z$ for the first time through acquiring the justification from $x$ for $y$ and deducing $z$ from $y$. For $S$ must already be justified to believe $z$ before this process of transmission could take place. This is a non-trivial case of transmission failure.

Although Wright's analyses of transmission and failure of transmission apply to justification sufficient for outright belief, these analyses can be reformulated to apply to degrees of justification (which may or may not suffice to sustain outright belief). Suppose there is initially no degree of justification for $y, z$ or their logical negations. We can say that the degrees of justification that $x$ supplies for $y$ transmit to $z$ across the entailment just in case this conditional is non-vacuously true:

If $S$ acquires from $x$ some degree of justification for $y$ and deduces $z$ from $y, S$ thereby acquires for the first time some degree of justification for $z$.

A trivial case of transmission failure of degrees of justification is instantiated if the above conditional is vacuously true. And a non-trivial case of transmission failure of degrees of justification is instantiated 
if the above conditional is false. There is a condition sufficient for transmission failure of degrees of justification that parallels Wright's, which is this:

The degrees justification that $x$ confers on $y$ are conditional on the existence of some degree of independent justification for $z$ (i.e. $x$ could give $S$ some degree of justification for $y$ only if $S$ had some degree of independent justification for $z$ ).

Suppose this condition is fulfilled. If $S$ has no degree of independent justification for $z, S$ will not acquire from $x$ any degree of justification for $y$ in the first instance. This is a trivial case of transmission failure because there are simply no degrees of justification to be transmitted to $z$. On the other hand, if $S$ has some degree of independent justification for $z, S$ will acquire from $x$ some degree of justification for $y$, but $S$ will not acquire degrees of justification for $z$ for the first time through acquiring the degrees of justification from $x$ for $y$ and deducing $z$ from $y$. For $S$ must already have some degree of justification for $z$ before the process of transmission could take place. This is a non-trivial case of transmission failure. From now on whenever I speak of transmission and transmission failure, I always refer to transmission and transmission failure of degrees of justification.

\section{Perceptual justification can transmit from $h$ to $\diamond h$}

Let $h$ be any ordinary world hypothesis capable of being a content of $S$ 's sense experience, and let $s h$ be any sceptical alternative to $h$ conceivable by $S$. We could for instance take $h$ to be the proposition 'There is a apple here', ${ }^{14}$ and $s h$ to be the proposition 'There is no apple here but a vicious demon makes me hallucinate this apple and renders the deception undetectable'. Suppose $S$ has initially no

\footnotetext{
${ }^{14}$ If only shape, colour, consistency, location etc. can genuinely be represented by our sense experiences, to say that $S$ has the experience as if there is a apple here is to say, roughly, that $S$ has the experience as if there is a solid red-coloured object of such and such a shape here.
} 
sensory evidence for $h, \sim h,{ }^{15} s h$ or $\sim s h$ and thus no degree of justification for any of them. Also suppose that $S$ has no evidence for $\diamond h, \sim \nabla h, \diamond s h$ or $\sim \nabla s h$ and thus no degree of justification for any of these propositions. The second supposition requires us to assume that conceivability (and any similar faculty a priori) is no source of evidence for metaphysical possibility. Imagine now that $S$ happens to have the sense experience as if $h$, and consider the deductive argument from $h$ to $\diamond h$. It is strongly intuitive (at least to me) that the argument from $h$ to $\diamond h$ will instantiate transmission of justification. In other words, as $S$ has the sense experience as if $h, S$ will acquire some justification for believing $h$ that will transmit for the first time to $S$ 's belief that $\nabla h$ as soon as $S$ realises that $h$ entails $\nabla h$. This intuition can be vindicated by appealing to liberalism about perceptual justification. ${ }^{16}$ An influential version of liberalism - called dogmatism - has been defended by Pryor (2000). (Similar positions have been proposed by, among others, Pollock 1986 and Huemer 2001).

According to Pryor:

(D) [For many content of perception $p]$, ${ }^{17}$ whenever you have an experience of $p$ 's being the case, you thereby have immediate (prima facie) justification for believing $p$. (Pryor 2000: 532).

A subject $S$ is immediately justified to believe $p$ if and only if $S$ is justified to believe $p$ and this justification is not based, not even in part, on any degree of independent justification that $S$ has for any proposition. ${ }^{18}$ For instance:

\footnotetext{
${ }^{15}$ Where ' $\sim$ ' is logical negation.

${ }^{16}$ Liberalism in epistemology of perceptions says that, roughly, $S$ 's sense experiences that can prima facie justify $S$ 's beliefs even if $S$ has no evidence for ruling out the hypotheses entailing that $S$ 's sense experiences are not veridical and provided that $S$ has no evidence in favour of any of these hypotheses (cf. Pryor 2004: 354).

${ }^{17}$ We should probably exclude any $p$ that describes the experience of something apparently impossible - like in Escher's paintings. Experiences of this type would give $S$ a reason to distrust her perceptions. ${ }^{18}$ See Pryor (2005) and Siegel and Silins (2013) for detailed analyses of the notion of immediate justification.
} 
An experience as of there being hands seems to justify one in believing there are hands in a perfectly straightforward and immediate way ... The mere fact that one has a visual experience of that phenomenological sort is enough to make it reasonable for one to believe that there are hands. No premises about the character of one's experience - or any other sophisticated assumptions - seem to be needed ... Our perceptual beliefs in these propositions are indeed justified in a way that does not require any further beliefs or reflection or introspective awareness. (Pryor 2000: 536).

Pryor suggests that experiences can immediately justify their contents because of their distinctive phenomenology, which he describes as 'the feeling of seeming to ascertain that a given proposition $[p]$ is true' (Pryor 2004: 357. Cf. also Pryor 2000: 547, note 37). Pryor's intuition is that this phenomenology alone suffices to give $S$ a defeasible reason for taking $p$ to be true. Although there are various ways to defend the thesis that experiences can immediately justify their contents (for an overview see Siegel and Silins 2013), I find Pryor's suggestion insightful. White (2006) has puts forward Bayesian objections to (D), but the soundness of these arguments has forcefully been questioned by, for instance, Weatherson (2007), Kung (2010b), Pryor (2013) and Moretti (2013). For responses to objections of different type to dogmatism see Siegel and Silins (2013). In general I find Pryor's dogmatism and - more generally - liberalism about perceptual justification quite solid and plausible.

Let us go back to our ordinary world hypothesis $h$. Remember that $S$ has no degree of justification for $h, \diamond h$ and their negations. According to the dogmatist, as $S$ has the sense experience as if $h, S$ will acquire prima facie immediate justification for believing $h$. Note that $S$ 's having immediate justification for $h$ doesn't seem to require $S$ to have any degree of independent justification for $\diamond h .^{19}$ Thus, once $S$

${ }^{19} S$ 's having immediate justification for the belief that $h$ requires $S$ to possess the concepts involved in that belief, which may require $S$ to have other beliefs and perhaps justified beliefs (note that it doesn't seem to follow from this that $S$ 's justification for the belief that $h$ is based, even in part, on the 
acquires this justification for $h$ and deduces $\diamond h$ from $h$ - since justification is presumably closed

under known entailment $-S$ will acquire for the first time prima facie justification for $\diamond h$. In

conclusion, the perceptual justification for $h$ will transmit to $\diamond h$.

Immediate justification comes as prima facie justification because it can be defeated by further

evidence. Whether immediate justification is also all things considered justification depends on what other evidence $S$ possesses and on whether or not this evidence acts as a defeater of the prima facie justification (cf. Pryor 2000: 534 and 545, note 28). For instance, if $S$ had prima facie immediate justification for $h$ based on her sense experience as if $h$, this justification would be defeated if $S$ had evidence supporting some sceptical alternative $s h$. I return to this in $\S 7$.

\section{Perceptual justification cannot transmit from $s h$ to $\diamond$ sh}

Suppose again that $S$ happens to have the sense experience as if $h$ and consider any sceptical alternative $s h$ to $h$ conceivable by $S$. Since $s h$ is not the content of $S$ 's sense experience but, rather, a hypothesis incompatible with it, it is implausible that $S$ 's sense experiencing as if $h$ could give $S$ immediate justification for believing $s h$ - even some degree of immediate justification. ${ }^{20}$ My suggestion is that what could provide $S$ 's with some justification for $s h$ when $S$ has the sense experience as if $h$ is, not this sense experience, but $S$ 's introspective experience as if she is having this sense experience. Consider a

justification for those other beliefs. Cf. Pryor 2000: 533-534 and Pryor 2005: 183). It seems very implausible, however, that those beliefs should include the one that $\nabla h$.

${ }^{20}$ Siegel and Silins (2013) discuss a number of different explanations of how experiences can provide immediate justification for propositions on the basis of their contents. On none of them it is plausible that $S$ 's sense experience as if $h$ could give $S$ some justification for $s h$. Consider for instance Pryor's suggested explanation. $S$ 's feeling of seeming to ascertain that $h$ is true cannot give $S$ any reason for believing that a proposition incompatible with $h-$ i.e. $s h-$ is true. 
proposition $y$ that aims to describe a contingent state of affairs and a piece of evidence $x$. It seems to me that there are at least two ways in which $x$ can be evidence that $y$ for a subject $S$ : (a) $x$ is $S$ 's very experience as if $y$, and (b) $x$ is $S$ 's experience of something that, in $S$ 's view, would be only an effect or a part of $y$ if $y$ actualised. $S$ 's experience as if $h$ and $h$ individuate an instance of case (a). On the other hand, $S$ 's introspective experience as if $S$ is having the sense experience as if $h$ and $s h$ individuate an instance of case (b). Note in fact that $S$ 's introspective experience as if $S$ is having the sense experience as if $h$ is the experience of something - i.e. $S$ 's sense experience as if $h$ - that, in $S$ 's view, would be just an effect or a part of $s h$ if $s h$ actualised. This is a principle that I believe to be true:

(P) For any $x$ and $y$ of type (b), $S$ 's having $x$ could give $S$ some degree of justification for $y$ only if $S$ had some degree of independent justification for $\diamond y$.

Consider now the deductive argument from $s h$ to $\diamond s h$. Remember that we assumed that $S$ has initially no evidence for $s h, \sim s h, \diamond s h$ or $\sim \diamond s h$, and thus no degree of justification for each of these propositions. Given (P), when $S$ has the introspective experience as if $S$ is having the sense experience as if $h$, the argument from $s h$ to $\diamond s h$ instantiates a trivial case of transmission failure. In other words, since $S$ has no degree of independent justification for $\diamond s h$ when $S$ has that introspective experience, $S$ will acquire no degree of justification for $s h$ in the first instance. ${ }^{21}$ The remainder of this section is devoted to defend $(\mathrm{P})$.

${ }^{21}$ It seems to me that $s h$ could also stand for the extreme idealist scenario according to which there is only the bundle of $S$ 's experiences caused by nothing at all. This scenario coincides with the bundle of $S$ 's experiences and the absence of any cause for them. Although this is admittedly a limiting case, $S$ 's experiences and $s h$ together single out a situation of type (b). Since it is rather unclear whether it is metaphysically possible that $S$ 's experiences could exist without any cause, (P) applies to this case too. 
To show that $(\mathrm{P})$ is true, or at least very plausible, we should show that the relation that makes it the case that $x$ confers some degree of justification on $y$ in the situations of type (b) requires $\diamond y$ to be independently justified to some degree. It seems to me that the two major conceptions (or families of conceptions) of the justification-making relation available today that most naturally apply to the cases of type (b) are explanationism and one view loosely identifiable with Bayesianism. ${ }^{22}$ The first conception applies if the content of $x$ - let's call it $p^{23}$ - is suitable to be related to $y$ by an explanatory relation, which happens in many (b)-cases. The second conception appears applicable to all (b)-cases in which we can determine the prior probabilities of $p$ and $y$. Let's consider each of these conceptions in turn.

Explanationism - in its purest form - maintains that all ampliative inferences are explanatory inferences, in the sense that all ampliative inferences provide justification for their conclusions - when they actually do so - in virtue of the potential explanation they supply (cf. Lycan 2002). As I have indicated in $\S 3$, the thesis that explanatory force is per se truth-conducive is hard to defend. Suppose nevertheless that explanationism is invoked. Let me outline an argument that shows that the explanationist is committed to $(\mathrm{P})$.

The explanationist would very probably claim that in any (b)-case, if $S$ 's having $x$ gives $S$ some degree of justification for $y$, this happens in virtue of S's being is in a position to ascertain that $y$ potentially explains $p$ (i.e. the content of $x$ ) to some extent. Where $y$ potentially explains $p$ (to some

\footnotetext{
${ }^{22}$ I put aside hypothetico-deductivism, which has a number of awkward and counterintuitive features. See for instance Gemes (1998 and 2005) and Pack (2004). I follow the majority in methodology in taking Bayesianism to have superseded hypothetico-deductivism.

${ }^{23}$ Thus, if $x$ is the sense experience as if $p, p$ is the content of $x$. If $x$ is $S$ 's introspective experience as if $S$ has the sense experience as if $q$, the content of $x$ is the proposition $p$ that $S$ has the sense experience as if $q$.
} 
extent) just in case if $y$ were true, $y$ would actually explain $p$ (to some extent). (Cf. Lycan 2002: 413, Ylikoski and Kuorikoski 2010: 202 and Schupbach and Sprenger 2011: 107 note 4). The explanationist appears thus committed to claiming that in any (b)-case, $S$ 's having $x$ gives $S$ some degree of justification for $y$ only if $S$ is in a position to be independently justified in believing (or to independently know) that $y$ possesses each of the properties necessary to make $y$ a potential explanation of $p$. These properties should include those that, if $y$ happened to be true, would enable $S$ to understand why $p$ is the case (e.g. the property of entailing a suitable lawlike principles, suitable unifying principles or descriptions of suitable causal mechanisms). These properties should also include the one of being metaphysically possible. For if $y$ weren't metaphysically possible, $y$ couldn't be true. Hence $y$ couldn't potentially explain anything to any extent. ${ }^{24}$ The explanationist appears thus committed to maintaining that in any (b)-case, $S$ 's having $x$ gives $S$ some degree of justification for $y$ only if $S$ is in a position to be independently justified in believing that $y$ is metaphysically possible. The explanationist should thus acknowledge that for any $x$ and $y$ of type (b), if $S$ had no degree of independent justification for the claim that $y$ is metaphysically possible, $S$ 's having $x$ could give $S$ no degree of justification for $y$. In conclusion the explanationist appears to be committed to $(\mathrm{P}) .^{25}$

\footnotetext{
${ }^{24}$ A complaint might be that if $y$ weren't metaphysically possible, the subjunctive conditional used to characterise the notion of $y$ 's being a potential explanation of $x$-i.e. if $y$ were true, $y$ would actually explain $p$ - would prove vacuously true on standard Lewis semantics. But this result wouldn't certify that $y$ is a potential explanation of $p$, for it would obtain irrespective of any of $y$ 's explanatory features (it obtains for instance if $y=$ ' $2+2=13$ ' and $x=$ 'the cat is on the mat'). This upshot seems only confirm that conditionals can display awkward features.

${ }^{25}$ A reviewer of this Journal suggests that an explanationist sympathetic to coherentism might reject my argument by claiming that since coherentist justification is holistic, $S$ 's justification for $\forall y$ cannot be independent of $S$ 's justification for $y$. Some coherentists in fact maintain that within an overall belief system the justification of any belief depends on the justification of any other belief. I agree with Murphy (2006: $\S 3 a$ ) that this extreme form of holism is very implausible. Suppose epistemological holism of this sort is true. If my beliefs about, say, what I had for breakfast a week ago were strongly incoherent and thus unjustified, my justification for my coherent beliefs about, say, the geography of Europe and arithmetic would also be destroyed. This would make the justification for my belief that the
} 
Let us turn to the Bayesian conception of the justification-making relation. The Bayesian assumes that degrees of rational beliefs - or credences - obey the probability calculus. The Bayesian conception of the justification-making relation identifies degrees of justification with degrees of rational beliefs (or, at any rate, it assumes that degrees of rational beliefs can accurately model degrees of justification). A consequence is that degrees of justification are taken to obey the probability calculus too. A view of this type underlies for instance the Bayesian construals of traditional sceptical arguments abundantly available in the literature. ${ }^{26}$

Consider $S$ 's experience $x$ with content $p$, and proposition $y$. The Bayesian framework requires us to model $S$ 's having the experience as if $p$ as a case of $S$ 's learning $p \cdot{ }^{27}$ Let Pr be $S$ 's credence function before $S$ 's learning $p$ and let $\operatorname{Pr}_{p}$ be $S$ 's credence function upon her learning $p$. On this conception of the justification-making relation, $S$ 's learning $p$ gives $S$ some degree of justification for $y$ only if $\operatorname{Pr}_{p}(y)>$ $\operatorname{Pr}(y)$. Namely, only if $S$ 's credence in $y$ upon her learning $p$ exceeds $S$ 's credence in $y$ before her learning $p . \operatorname{Pr}_{p}(y)$ can be determined via conditionalisation by imposing that as $S$ learns $p, \operatorname{Pr}_{p}(y)=$

UK is in Europe and my belief that $2+2=4$ depend on the justification for my belief that I had eggs for breakfast a week ago, which appears absurd. According to Murphy, the coherentist should - more plausibly - organise an overall belief system into subsystems on the grounds of, for instance, the beliefs' subject-matters or their sources. In this way, lack of coherence, and so justification, for a subsystem would normally result in no lack of coherence, and so justification, for another subsystem. In conclusion, I doubt that an explanationist sympathetic to coherentism could adduce epistemological holism to argue that $S$ 's justification for $\diamond y$ cannot be independent of $S$ 's justification for $y$ without rendering her philosophical view quite implausible or unpalatable. Note that $S$ 's belief that $\Delta y$ and $S$ 's belief that $y$ are about very different subject-matters.

${ }^{26}$ Cf. White (2006) and Schiffer (2004 and 2009).

${ }^{27}$ Note that if $S$ experiences as if $p$, it follows neither that $S$ believes $p$ nor that $p$ is true. On the other hand, if $S$ learns that $p$, it follows both that $S$ believes $p$ and that $p$ is true. One might thus contend that the Bayesian model is flawed because misrepresentative. But I'm not sure this would be a reason sufficient to drop this formalisation - models are allowed and indeed expected to include idealisations and approximations. More importantly, note that the Bayesian model is not misrepresentative when $S^{\prime}$ s experience is a reflective experience, which is the case we are specifically concerned with here. For if $S$ has the reflective experience as if $p, S$ presumably believes $p$ and $p$ is true or very probably true. 
$\operatorname{Pr}(y \mid p)$ and $\operatorname{Pr}_{p}(p)=1$. That is to say, as $S$ learns $p, S$ 's credence in $y$ equates the conditional credence in $y$ given $p$ that $S$ had before learning $p$, and $S$ becomes certain that $p$.

Suppose now that before learning $p, S$ has no degree of justification for $\diamond y$ in the sense that $S$ 's degree of justification for $\diamond y$ is just zero or cannot be determined (because $S$ has no evidence for $\diamond y$ or $\sim \nabla y$ ). If degrees of justification correspond to credences, before learning $p, S$ has no degree of belief in $\diamond y$, in the sense that $\operatorname{Pr}(\diamond y)$ is zero or cannot be determined. Since $y$ implies $\diamond y$, through the probability calculus, $\operatorname{Pr}(y) \leq \operatorname{Pr}(\diamond y)$. Since $\operatorname{Pr}(\diamond y)$ is zero or cannot be determined, it follows that $\operatorname{Pr}(y)$ is zero or cannot be determined. Note now that $\operatorname{Pr}(y \mid p)$ is defined as $\operatorname{Pr}(y \& p) / \operatorname{Pr}(p)$ (with $\operatorname{Pr}(p)>0)$. Since $y \& p$ entails $y, \operatorname{Pr}(y \& p) \leq \operatorname{Pr}(y)$. Since $\operatorname{Pr}(y)$ is zero or cannot be determined, $\operatorname{Pr}(p \& y)$ and the ratio $\operatorname{Pr}(y \&$ p) $/ \operatorname{Pr}(p)$ are both zero or cannot be determined. Consequently $\operatorname{Pr}(y \mid p)$ is zero or cannot be determined. ${ }^{28}$ Hence, through conditionalisation, $\operatorname{Pr}_{p}(y)$ is zero or cannot be determined. ${ }^{29,}{ }^{30}$ The result is that, if $S$ has

\footnotetext{
${ }^{28}$ We attain the same result if conditional probabilities are taken to be primitive. Suppose $t$ is a tautology. It seems very plausible that if $\operatorname{Pr}(y)$ is zero or cannot be determined then $\operatorname{Pr}(y \mid t)$ is also zero or cannot be determined. Even if conditional probabilities are taken to be primitive, it is true that $\operatorname{Pr}(y \mid p)=\operatorname{Pr}(y \mid p \& t)=\operatorname{Pr}(y \& p \mid t) / \operatorname{Pr}(p \mid t)$ with $\operatorname{Pr}(p \mid t)>0$. Furthermore, since $y \& p$ entails $y, \operatorname{Pr}(y \& p \mid t)$ $\leq \operatorname{Pr}(y \mid t)$. As $\operatorname{Pr}(y \mid t)$ is zero or cannot be determined, $\operatorname{Pr}(y \& p \mid t)$ is zero or cannot be determined. Thus $\operatorname{Pr}(y \& p \mid t) / \operatorname{Pr}(p \mid t)$ is zero or cannot be determined. So $\operatorname{Pr}(y \mid p \& t)$ and thus $\operatorname{Pr}(y \mid p)$ is zero or cannot be determined.

${ }^{29}$ If we switch from standard to Jeffrey conditionalisation the conclusion is identical. Jeffrey conditionalisation enables $S$ to update her credence in $y$ on the grounds of a mere change in her credence in $p$ that may not coincide with $S$ 's becoming certain that $p$. One might insist that in the (b)cases we are particularly interested in - i.e. those in which $S$ has the introspective experience as if $p-S$ "learns" $p$ in the sense that her credence in $p$ becomes only close to 1 . On Jeffrey conditionalisation $\operatorname{Pr}_{p}(y)=\operatorname{Pr}_{p}(p) \operatorname{Pr}(y \mid p)+\operatorname{Pr}_{p}(\sim p) \operatorname{Pr}(y \mid \sim p)$. We saw that since $\operatorname{Pr}(y)$ is zero or cannot be determined, $\operatorname{Pr}(y \mid p)$ is zero or cannot be determined. By a parallel argument one can show that since $\operatorname{Pr}(y)$ is zero or cannot be determined, $\operatorname{Pr}(y \mid \sim p)$ is zero or cannot be determined. It follows that $\operatorname{Pr}_{p}(y)$ is zero or cannot be determined via Jeffrey conditionalisation.

${ }^{30}$ To model the situation in which $\operatorname{Pr}(\diamond y)$ cannot be determined because $S$ has no evidence for $\diamond y$ or $\sim \nabla y$, one might suggest to replace sharp with imprecise probabilities - i.e. intervals or sets of probabilities. In that case $\operatorname{Pr}(\diamond y)$ should be given the whole closed interval $[0,1]$. I cannot analyse the consequences of using this non-standard Bayesian framework here. I make only two basic remarks: first, an unsolved problem of the imprecise probabilities framework, which puts its applicability at risk, is the dilation one (cf. White 2010 and Joyce 2010). Second, if $\operatorname{Pr}(\diamond y)$ 's interval includes zero, after conditionalising on $p$ by using standard or Jeffrey conditionalisation, the probability set ascribed to
} 
no degree of independent justification for $\diamond y, \operatorname{Pr}(y)$ and $\operatorname{Pr}_{p}(y)$ are both zero or cannot be determined.

Thus it is untrue that $\operatorname{Pr}_{p}(y)>\operatorname{Pr}(y)$. So it is untrue that $S$ 's learning $p$-i.e. $S$ 's having the experience $x$ - gives $S$ some degree of justification for $y$. Those who embrace the Bayesian view of the justificationmaking relation are committed to $(\mathrm{P})$.

Let me now consider a possible objection. As we have seen, my argument assumes that if $S$ has no evidence for $\diamond y$ or $\sim \diamond y, \operatorname{Pr}(\diamond y)$ cannot be determined. Bayesian objectivists and subjectivists are likely to raise objections. The objectivist might contend that since $S$ is bound to determine her credences in $\diamond y$ and $\sim \nabla y$ by using some version of the principle of indifference, $\operatorname{Pr}(\diamond y)$ and $\operatorname{Pr}(\sim \nabla y)$ should have determinate and non-zero values even if $S$ has no evidence for $\diamond y$ or $\sim \nabla y$. A basic formulation of the principle of indifference says that given a countable set of mutually exclusive and exhaustive hypotheses, if $S$ 's evidence doesn't favour some hypothesis over the others, $S$ should distribute equally her credence over all of them (cf. Weisberg 2011: 505-508). As $\diamond y$ and $\diamond y$ are mutually exclusive and exhaustive, and $S$ 's evidence cannot discriminate between them, $S$ 's credence in either hypothesis should be $1 / 2 .^{31}$ The Bayesian subjectivist, on the other hand, might contend that given that $S$ lacks any evidence for $\diamond y$ and $\sim y, S$ is rationally entitled to determine $\operatorname{Pr}(\diamond y)$ as she likes, by following her intuitions and inclinations, provided the assigned value is probabilistically coherent. ${ }^{32}$

$\operatorname{Pr}_{p}(\diamond y)$ 's will still include zero (cf. Hájek 1998). One may thus doubt that $S$ 's credence in $y$ has actually been bolstered, and that $S$ has acquired any degree of justification for $y$ from $p$.

${ }^{31}$ Note that the principle of indifference is very controversial because yields results apparently incoherent. See for instance Howson and Urbach (1996: 266ff). White (2010) has defended this principle. See Dodd (2012)'s rejoinder.

32 And perhaps it satisfies minimal formal constraints (e.g. Jeffrey requires Pr to assign 0 and 1 only to, respectively, contradictions and tautologies). 
My response challenges the adequacy of both objectivism and subjectivism when degrees of rational belief are taken to model degrees of epistemic justification - as in the case in point. It is natural to assume that $S$ 's degrees of rational belief can accurately model $S$ 's degrees of epistemic justification only if the type of rationality displayed by $S$ 's beliefs is specifically epistemic (rather than, say, practical or moral). Nowadays there is wide consensus (among epistemologists sympathetic to internalism at least) that our credences are epistemically rational only if they are properly supported by evidence (see for instance Kelly 2003). If $S$ distributed her credences on $\diamond y$ and $\sim y$ in accordance with objectivism or subjectivism, her credences would fail to be epistemically rational because they would be supported by no evidence whatsoever. It would be hard, then, to understand how these credences could represent degrees of epistemic justification.

\section{If conceivability per se is no source of evidence for metaphysical possibility the UA fails}

What conclusions should we draw from the upshots of the last two sections? We have taken $h$ to be any ordinary world hypothesis capable of being a content of $S$ 's sense experience, and $s h$ to be any sceptical alternative to $h$ conceivable by $S$. We have assumed that $S$ has initially no degree of justification for $h$, $\diamond h$ or their negations. We have seen that as $S$ experiences as if $h, S$ acquires prima facie immediate justification for believing $h$, which could be defeated by $S$ 's evidence in favour of any $s h$. The sceptic can insist that the UA can be interpreted as stating that $S$ always has defeating evidence of this type. ${ }^{33}$ In short, when $S$ has the sense experience as if $h, S$ also has the introspective experience as if she is

${ }^{33}$ This would be a possible objection to the alleged antisceptical consequences of Pryor (2000 and 2004)'s dogmatism. Interestingly, Moretti (2013) argues that White (2006)'s objections to dogmatism are of just this type in that they exploit the introspective or reflective side of sensory evidence. 
having the sense experience as if $h$. This introspective experience gives $S$ some justification for believing the disjunction of all shs. This undermines $S$ 's prima facie justification for $h$. The result might appear to be that, all things considered, $S$ 's sensory evidence (constituted by $S$ 's sense experience as if $h$ and $S$ 's introspective experience as if she is having that sense experience) supports $h$ no more than any $s h$. In our thought experiment we have assumed, however, that $S$ has initially no evidence for $\diamond s h$ or $\sim \diamond_{s} h$, and thus no degree of justification for $\diamond s h$, for any sceptical alternative $s h$ to $h$ conceivable by $S$. Consequently - I have argued $-S$ can acquire no degree of justification for the disjunction of all shs. This means that $S$ 's prima facie immediate justification for believing $h$ stands undefeated. All things considered, $S$ 's sensory evidence justifies $h$ more than any $s h$. This falsifies (1).

I have shown that if $S$ has no evidence for believing that the sceptical alternatives to $S$ 's contents of perception are metaphysically possible, the UA fails. From this we cannot yet conclude that if conceivability is no source of evidence for metaphysical possibility, the UA fails. A concern could be that evidence for metaphysical possibility might have a different source and that evidence coming from this different source might enable the UA to go through. Let me dispel this final concern.

To begin with, note that a sceptical alternative $s h$ to $h$ may be conceived of by $S$ as capable of causing many of her sense experiences in addition to the experience as if $h$. But it seems plausible that none of these independent experiences would be able to give $S$ any justification for $\diamond$ sh. If $\diamond$ sh is not independently justified for $S$, all these experiences would only instantiate trivial transmission failure. The theory-laden conception of experience says that background belief or dispositional abilities to recognize an object or property influence phenomenology and content of experience. The sceptic might perhaps try to appeal to the theory-laden conception to claim that $S$ could have the very experience as if 
$s h-$ e.g. the experience as if she is deceived by a computer or a demon into seeing an apple - if $S$ were provided with the right background belief or the right dispositional abilities. An experience with content $s h$ would arguably give $S$ prima facie immediate justification for $s h$ that would transmit to $\diamond s h$. I would find this argument unconvincing. Even though our experiential contents seem to be somewhat theory-laden (cf. Siegel 2012), one can legitimately doubt that $S$ could arrive at having the very experience as if she is in a sceptical scenario. The sceptic should give us evidence that this is actually possible. ${ }^{34}$ Furthermore, as a matter of fact we do not have the extraordinary belief background or dispositional abilities that would allegedly produce in us the experience as if we are in a sceptical scenario. And it is unclear why we shouldn't consider the perceptual beliefs of anyone who had that extraordinary belief background or dispositional abilities to be aberrant or inappropriate from an epistemic viewpoint. $^{35}$

Global sceptics sometimes pave the way for their master arguments by describing cognitive mistakes we are typically subject to (e.g. Descartes' stick immersed in water that looks bent). It is intuitive that these examples can give $S$ some degree of justification for believing that it is metaphysically possible that $S$ can incur similar ordinary and detectable cognitive errors. But it seems implausible that these examples could give $S$ some degree of justification for the claim that it is

\footnotetext{
${ }^{34}$ For example, it seems plausible (at least to me) that whatever background belief $S$ might have, she will not be able to have the physical components of the computer or the mental processes of the demon genuinely represented in her experience.

${ }_{35}$ This would probably require revising the notion of immediate justification along the lines suggested by for instance Silins (2007).
} 
metaphysically possible that an extraordinary deceiving situation - one that could never be detected by $S$ - actualises. $^{36}$

Van Inwagen (2001) and Kung (2011), among others, emphasise that we seem to be able to know the modal status of propositions when they describe situations similar to those of ordinary life. A nonimplausible explanation of this ability is roughly the following: in these cases, our mind recombines into novel scenarios things that we know or we have justification to believe to exist and to have certain properties on the grounds of our experience. Many find it intuitive that recombination processes of this type can give us knowledge or at least some justification for believing that the envisaged situations are metaphysically possible. (Note that our mind recombines things into novel scenarios by imagining or conceiving of the scenarios. But this doesn't require imagination or conceivability as such to be sources of evidence for metaphysical possibility. This view only demands that specific uses of these faculties, which heavily rely on a posteriori evidence, be able to track metaphysical possibility). Views broadly of this type have been defended for instance by Kung (2010a), Denby (2008) and Bricker (1991).

A sceptic sympathetic to recombinatorialism might argue that we possess some degree of justification for claiming that sceptical scenarios that include no outlandish entities - such as disembodied souls or vicious demons - are metaphysically possible (cf. Kung 2011). This might be the

\footnotetext{
${ }^{36}$ An argument for global scepticism that I heard in discussion says that we might incur potentially endless sequences of ordinary cognitive errors in which any new error wipes out the evidence of our previous error. The argument could be formulated as a version of the UA in which the shs stand for sequences of this type. I don't find this version of the UA plausible in the least. Given our empirical evidence, we should reasonably conclude that sceptical alternatives of this sort are extremely improbable. One might respond that we cannot trust our judgments of probability when the UA comes into play, as the UA is meant to undermine all empirical evidence, including the grounds of our judgments of probability. If this is true, we can legitimately ask why we should still trust our judgments of metaphysical possibility and apply the counterargument of this paper.
} 
case with the brain-in-a-vat scenario and the Matrix scenario. ${ }^{37}$ The impression could be that these two scenarios can be assembled by recombining various things the existence of which is known because attested by our sensory evidence - e.g. computers, brains and subjective experiences.

Under closer scrutiny it is far from clear, however, that the brain-in-a-vat scenario or the Matrix scenario would obtain via recombining existing things. Admittedly, present technology doesn't look sufficiently sophisticated to enable us to assemble these two scenarios. The impression that these scenarios are attainable by recombining existing things seems in fact to rest on the assumption that we will or would produce technological tools necessary for the recombination that we do not have yet (e.g. more powerful computers). But why should we grant this assumption? We shouldn't confuse suggestions from science fiction with real scientific knowledge. Perhaps the basic components of the universe are such that they cannot be recombined in the required way. For example, a device capable of giving us the right feedback to reproduce elementary experiences in a perfect way (like grabbing a chair or walking in the street) might simply be unattainable. For it might turn out that too many data would need to be processed in a too little time. (Cf. Dennett 1991: 5).

The global sceptic appealing to recombinatorialism would face another difficulty described in Kung (2011: $\S \S 3$ and 4). The sceptic could appeal to recombinatorialism only if she conceded that part of our description of the world is not underdetermined by the scenarios obtained via recombination. According to the recombinatorialist, in order for $S$ to have some justification that scenarios like the brain-in-a-vat or the Matrix are metaphysical possible, $S$ needs to possess justification for at least some

${ }^{37}$ The second scenario differs from the first only because our brains are still kept in our insentient bodies. 
ordinary world hypotheses and scientific hypotheses: those that describe the sort of things to be

recombined to produce these scenarios. Let's call $T$ the conjunction of these hypotheses. No scenario sh attainable by recombining things that $T$ describes and states to exist could constitute an alternative to $T$. For considering any such $s h$ to be metaphysically possible requires taking $T$ to be true or justified. If $s h$ were underdetermined $T$, this would destroy the degrees of justification that $S$ has for believing $\oslash_{s h}{ }^{38}$ Thus even if recombinatorialism enabled $S$ to have epistemic access to metaphysical possibility, recombinatorialism could not make the UA work, for $S$ would be required to know some propositions about the external world. The appeal to recombinatorialism might perhaps help local sceptics, but it cannot help the global sceptic (cf. Kung 2011: 13). As I cannot think of any further potential source of evidence for metaphysical possibility, ${ }^{39}$ I conclude that if conceivability or a similar faculty a priori is per se no source of evidence for metaphysical possibility, the UA doesn't go through.

\footnotetext{
${ }^{38}$ A reviewer of this Journal suggests that if the appeal to recombinatorialism were successful, $S$ would be trapped in a sort of endless loop that would make the non-sceptical position unstable. Suppose $s h$ is the all-encompassing theory, incompatible with $T$, that $S$ is a brain in a vat and the whole world is just a hallucination of $S$ produced by a computer. Imagine $S$ is initially empirically justified to believe $T$. If recombinatorialism is successful, $S$ 's justification for $T$ gives $S$ some justification for $\nabla s h$. This makes the premise (1) of the UA that features both $T$ and $s h$ true. Hence, through the UA, $S$ is deprived of her initial justification for $T$. Consequently, $S$ is also deprived of her justification $\diamond s h$. This makes (1) false, restores $S$ 's original justification for $T$ and takes $S$ back to the first step. And so on. Despite the appearance, I think that $S$ is trapped in no loop. For if recombinatorialism is successful, $S$ 's justification for $T$ gives $S$ justification for, not just $\nabla$ sh, but the conjunction of $\nabla$ sh and $\sim s h$. This is so because $S$ 's justification for $\nabla s h$ is grounded in $S$ 's justification for $T$, which is incompatible with $s h$. Thus $S$ 's degrees of justification for $\nabla s h$ cannot but come together with $S$ 's justification for believing $\sim s h$. This makes (1) false and blocks the loop the outset. Kung (2011: $\S 3$ and 4) considers and rejects a similar objection.

39 Williamson (2010: Ch. 5) argues that our knowledge of metaphysical modality is a special case of our knowledge of counterfactuals, which in turn depends on our having knowledge of everyday facts and scientific and constitutive principles. Since Williamson's view is openly externalist, I'm not sure it is relevant for our discussion here, which presupposes internalism. Note at any rate that, like recombinatorialism, Williamson's modal epistemology rests on the assumption that we have knowledge of the external world. It seems thus improbable that the global sceptic could appeal to it.
} 


\section{It is dubious that conceivability per se is a source of evidence for metaphysical possibility}

The central thesis defended in this paper is conditional: if the UA succeeds, then conceivability, or a similar faculty a priori, is inherently a source of degrees of justification for metaphysical possibility. In the former sections, I have tried to substantiate the truth of this conditional. Before concluding, let me shed some doubt on its consequent - since the conditional is presumably true, its antecedent will also become dubious. The thesis that conceivability per se is epistemically linked with metaphysical possibility is quite controversial in contemporary philosophy. For instance, while Chalmers (2002 and 1999) and Yablo (2002 and 1993) notoriously believe that conceivability is (in different senses) a source of evidence for metaphysical possibility, Kung (2011a), Williamson (2010), Fiocco (2007), van Inwagen (2001), Tidman (1994) and D. Lewis (1986) all doubt (in different senses and to different degrees) that conceivability has this feature.

Rather than examining the arguments by these authors, let me just outline a basic problem for the thesis that conceivability per se supplies evidence for metaphysical possibility. ${ }^{40}$ This problem sometimes emerges in the literature, but for same reason is rarely directly addressed. For instance, though Gendler and Hawthorne (2006) acknowledge that it is a fact that a great number of modal epistemologists today agree with Chalmers or Yablo, they also emphasise that:

The idea that conceivability is a guide to metaphysical possibility is extremely problematic. According to current orthodoxy, metaphysical possibility can neither be reduced to, nor eliminated in favour of, linguistic rules and conventions; it constitutes a fundamental mindindependent subject-matter for thought and talk. Given this picture, it is rather baffling what sort of explanation there could be for conceiving's ability to reveal its character. It seems clear that the causal explanation for the reliability of perception is quite unsuitable here - and it is profoundly difficult to see what to put in its place. (2002: 6).

${ }^{40}$ For a different objection that I cannot present here see Nozick (2003: Ch. 3). 
Very similar perplexities are expressed by Vaidya (2007: §4) and Evnine (2008). Certainly not all philosophers stick to "current orthodoxy" about metaphysical possibility. But to perceive the UA to be a threat for the possibility of knowledge, we need to do so: for this purpose, metaphysical possibility cannot be thought of a something that can be reduced to, or eliminated in favour of, linguistic rules and conventions. To perceive the UA to be a threat for knowledge, we must think that it is objectively possible that, say, a vicious demon is deceiving us - this scenario must be a way the world could be. But, again, why should scenarios that we can just subjectively conceive of inherently reflect, or even reflect with only some degree of probability, the ways the objective world could be? What sort of metaphysical link could ever get this job done? One can reasonably doubt that a mysterious link of this type actually exists.

This is a difficulty of principle that cannot be settled by simply postulating that the cognitive link between conceivability per se and metaphysical possibility is fallible in nature or that this link can convey only some degree of justification. For to argue persuasively that this link is fallible or that can convey only weak justification, we have to say something substantive about the nature of this link. Consider for instance the notion of conceivability put forward by Yablo (1993), according to which:

(Con) For any proposition $p, p$ is conceivable for a rational subject $S$ if and only if $S$ can imagine a world that appears to $S$ to make $p$ true.

Imagination here should not necessarily be taken to require sensory presentations. Furthermore, in order to imagine a world, $S$ does not have to imagine all of it in detail. Yablo proposes the following general principle:

(M) If $p$ is conceivable for $S$, then $S$ has prima facie justification for believing that it is metaphysically possible that $p$. 
On (M), conceivability provides $S$ with only a fallible justification for believing that $p$ is possible.

The reason is - according to Yablo - that $S$ 's justification can be defeated if $S$ comes to recognize that the world that she has imagined and has taken to verify $p$ is not sufficiently fine-grained in detail to be one in which $p$ is true, ${ }^{41}$ or if $S$ finds out that $p$ is incompatible with a known necessary true proposition.

Imagine now that one appeals to (Con) and (M) to contend that since we can conceive of the outlandish scenario in which we are deceived by a malicious demon, we are at least prima facie justified in believing that it is metaphysically possible that we are deceived by a malicious demon. This claim can surely be questioned (independently of any consideration about whether the world is sufficiently fine-grained in detail to verify our sceptical conjecture). As long as the nature of the supposed cognitive link between conceivability per se and metaphysical possibility remains completely unexplained, one may reasonably doubt that there is any cognitive link whatsoever here. Thus one can reasonably deny that we are even prima facie justified to believe that it is metaphysically possible that we are deceived by a demon. For if there is no cognitive connection, it makes no sense to say that there is a prima facie justification. ${ }^{42}$ Indeed, it makes no sense to say that there is any degree of evidential support whatsoever, however weak we might assume it is.

${ }^{41}$ Consider for example the case in which $S$ imagines a world in which a computer generates some number and in which mathematicians take that number to falsify Goldbach's conjecture. This world might initially appear to $S$ to verify the proposition that Goldbach's conjecture is false. Yet, upon reflection, $S$ could acknowledge that this world does not verify that proposition because the situation that $S$ has imagined is compatible with the truth of the proposition that Goldbach's conjecture has no counter-example and the mathematicians are simply misled by that computer's output.

${ }^{42}$ Chalmers appeals to ideal conceivability (i.e. conceivability that cannot be undone by further rational reflection), and contends that ideal conceivability entails metaphysical possibility. But I do not see why ideal conceivability should cast a cognitive bridge between the subject's thoughts and independent facts about what is metaphysically possible. Furthermore, I doubt that the commonly adduced sceptical scenarios can be said to be ideally conceivable for us. 
I do not take this sketched objection to be just devastating. My modest objective here is suggesting that the claim that conceivability is inherently a source of degrees of justification for metaphysical possibility is contentious and may prove false at the end of the day. Although I have focused on conceivability and imagination, other alleged a priori sources of modal evidence - e.g. intuition, supposition, understanding, etc. - appear to me even more problematic than conceivability. My main criticism should apply, with minor changes, to these notions too.

\section{Conclusions}

The UA is probably the most direct and straightforward argument for global external world scepticism. I have made a case that the UA can go through only if the contentious thesis that conceivability or a similar faculty a priori is per se a source of evidence for our claims to metaphysical possibility is true. I have suggested that this thesis is false. This casts doubts on the soundness of the UA. An important question to be examined next is whether my response to the UA could be reformulated to counter other sceptical arguments, and specifically those that hinge on principles of epistemic closure.

\section{Acknowledgments}

I am grateful to very many people for comments and criticism on drafts of this paper or sections of it. Not all remarks and objections have been embedded or considered in the final draft. I would like to thank in particular: Yuval Avnur, Guido Bacciagaluppi, Francesco Berto, Andrea Bianchi, Björn Brodowski, Vincenzo Crupi, Franz Dietrich, Paul Dicken, Dylan Dodd, Filippo Ferrari, Branden Fitelson, Peter Graham, Gerry Hough, Balint Kekedi, Peter Kung, Mogens Laerke, Elisabetta 
Lalumera, Federico Luzzi, Philip Meadows, Walter Moretti, Sebastiano Moruzzi, Nikolaj Pedersen, Tommaso Piazza, James Pryor, Grant Reaber, Charles Travis, Giorgio Volpe, Crispin Wright, Masahiro Yamada, Elia Zardini and two reviewers of this Journal. I am also very grateful to audience at the 2010 Southern California Epistemology Workshop in UCLA, the Cogito research group of the University of Bologna, the Northern Institute of Philosophy (NIP), and the Departments of Philosophy of the University of Aberdeen and the University of Porto. My research was supported by a Visiting Fellowship from the Tilburg Centre for Logic and Philosophy of Science, a Visiting Fellowship from the Munich Center for Mathematical Philosophy, and a Carnegie Grant from the Carnegie Trust for the Universities of Scotland.

\section{References}

Beebe, J. R. (2009). 'The Abductivist Reply to Skepticism'. Philosophy and Philosophical Research 79: 605-636.

Beebe, J. R. (2010). 'Constraints on Sceptical Hypotheses'. Philosophical Quarterly: 449-470.

Bonjour, L. (2002). Epistemology: Classic problems and contemporary responses. Lanham, MD: Rowman \& Littlefield.

Bonjour, L. (2003). 'A Version of Internalist Foundationalism'. In J. Bonjour and E. Sosa (eds), Epistemic Justification: Internalism vs. Externalism, Foundations vs. Virtues. Malden, MA: Blackwell, pp. 3-96.

Bricker, P. (1991). 'Plenitude of Possible Structures'. Journal of Philosophy 88: 607-619.

Brueckner, A. (1994). 'The Structure of the Skeptical Argument'. Philosophy and Phenomenological 
Research 54: 827-835.

Chalmers, D. (1999). 'Materialism and the Metaphysics of Modality'. Philosophy and Phenomenological Research 59: 473-496.

Chalmers, D. (2002). 'Does Conceivability Entail Possibility?'. In T. S. Gendler and J. Hawthorne (eds.) Conceivability and Possibility. Oxford: Clarendon Press, pp. 145-200.

Denby, D. (2008). 'Generating Possibilities’. Philosophical Studies 141: 191-207.

Dennett, D. (1991). Consciousness Explained. Boston: Little, Brown \& Co.

Dodd, D. (2012). 'Roger White's argument against imprecise credences'. British Journal for the Philosophy of Science (forthcoming).

Douven, I. (2011). 'Abduction'. In E. N. Zalta (ed.), The Stanford Encyclopedia of Philosophy. URL= $<$ http://plato.stanford.edu/archives/spr2011/entries/abduction/>.

Evnine, S. (2008). 'Modal Epistemology: Our Knowledge of Necessity and Possibility'. Philosophy Compass 3/4: 664-684.

Feldman, R. (2003). Epistemology. Upper Saddle River, NJ: Pearson Education.

Fiocco, M. O. (2007). 'Conceivability, imagination and modal knowledge'. Philosophy and Phenomenological Research 74: 364-80.

Gemes, K. (1998) 'Hypothetico-Deductivism: The Current State of Play; The Criterion of Empirical Significance Endgame'. Erkenntnis 49:1-20.

Gemes, K. (2005) ‘Hypothetico-Deductivism: Incomplete but Not Hopeless'. Erkenntnis 63:139-147.

Goldman, A. (2011). 'Reliabilism'. In E. N. Zalta (ed.), The Stanford Encyclopedia of Philosophy. $\mathrm{URL}=<$ http://plato.stanford.edu/archives/spr2011/entries/reliabilism/ $>$. 
Gendler, T. S. and J. Hawthorne (2002). 'Introduction: Conceivability and possibility'. In T. Gendler and J. Hawthorne (eds.), Conceivability and Possibility. Oxford: OUP, pp. 1-70.

Graham, P. (2007). 'The theoretical diagnosis of skepticism'. Synthese, 158: 19-39.

Graham, P. (2008). 'The relativist response to radical skepticism'. In J. Greco (Ed.), The Oxford Handbook of Scepticism. Oxford: OUP, pp. 392-413.

Hájek, A. (1998). ‘Agnosticism meets Bayesianism'. Analysis 58: 199-206.

Howson, C and P. Urbach (1996). Scientific Reasoning: the Bayesian Approach (2 ${ }^{\text {nd }}$ edition). Chicago and La Salle: Open Court.

Huemer, M. (2000). 'Direct Realism and the Brain-in-a-Vat Argument'. Philosophy and Phenomenological Research 61: 397-413.

Huemer, M. (2001). Skepticism and the Veil of Perception. Rowman \& Littlefield.

Jenkins, C. (2007). 'Entitlement and Rationality’. Synthese 157: 25-45.

Joyce, J. (2010). ‘A Defense of Imprecise Credences in Inference and Decision Making'. Philosophical Perspectives 24: 281-323.

Kelly, T. (2003). 'Epistemic Rationality as Instrumental Rationality: A Critique'. Philosophy and Phenomenological Research 66: 612- 640.

Klein, P. (2008). 'Skepticism'. In E. Zalta (Ed.), The Stanford Encyclopedia of Philosophy. URL = $<$ http://plato.stanford.edu/archives/fall2008/entries/skepticism/>.

Kung, P. (2009). 'What makes a good skeptical thought experiment?' Unpublished manuscript downloadable at: http://pages.pomona.edu/ pfk04747/research/papers.html. 
Kung, P. (2010a). 'Imagining as a guide to possibility'. Philosophy and Phenomenological Research 81: 620-633.

Kung, P. (2010b). 'On having no reason: dogmatism and Bayesian confirmation'. Synthese 177: 1-17.

Kung, P. (2011). 'On the Possibility of Skeptical Scenarios'. European Journal of Philosophy 19: 387407.

Levin, M. (2000). 'Demons, possibility and evidence'. Nô̂s 34: 422-440.

Lewis, D. (1986). On the Plurality of Worlds. Oxford: Blackwell.

Lycan, W. G. (2002). 'Explanation and epistemology'. In Paul K. Moser (ed.), The Oxford Handbook of Epistemology. Oxford: Oxford University Press, pp. 408-433.

Moser, P. K. (1989). Knowledge and Evidence. Cambridge: Cambridge University Press.

Moretti and Piazza (2013). 'Transmission of warrant and justification'. In E. Zalta (Ed.), The Stanford Encyclopedia of Philosophy. (Forthcoming).

Moretti (2013). 'In defence of dogmatism'. Unpublished Manuscript. Downloadable at: http://philpapers.org/rec/MORIDO-6.

Nozick, R. (2003). Invariances. Harvard: Harvard University Press.

Owens, D. (2000). 'Self-knowledge, externalism and scepticism, II - Scepticisms: Descartes and Hume'. Supplement to the Proceedings of the Aristotelian Society 74: 119-142.

Park, Suck-Jung. (2004) 'Hypothetico-Deductivism is still Hopeless'. Erkenntnis 60: 229-234.

Pollock, John (1986). Contemporary Theories of Knowledge. Towata, NJ: Rowman and Littlefield. 
Pritchard, D. (2005a). 'Wittgenstein's On Certainty and Contemporary Anti-Scepticism'. In D.

Moyal-Sharrock and W. H. Brenner (eds.) Readings of Wittgenstein's On Certainty. London: Palgrave Macmillian, pp. 189-224.

Pritchard, D. (2005b). 'The structure of sceptical arguments'. Philosophical Quarterly 55: 37-52.

Pryor, J. (2000). 'The skeptic and the dogmatist'. Noûs 34: 517-49.

Pryor, J. (2004). 'What's wrong with Moore's argument'. Philosophical Issues 14, Epistemology: 349378.

Pryor, J. (2005). 'Is there immediate justification?' In (eds.) M. Steup and E. Sosa, Contemporary debates in epistemology. Oxford: Blackwell, pp. 181-202.

Pryor, J. (2013). 'Uncertainty and undermining'. Unpublished Manuscript. Downloadable at: http://www.jimpryor.net/research/papers/Uncertainty.pdf

Schiffer, S. (2004). 'Skepticism and the vagaries of justified belief'. Philosophical Studies 131: 525557.

Schiffer, S. (2009). ‘Evidence = knowledge: Williamson's Solution to Skepticism’. In P. Greenough and D. Pritchard (eds.), Williamson on Knowledge. Oxford: OUP, pp. 183-202.

Schupbach J. and J. Sprenger (2011). 'The logic of explanatory power'. Philosophy of Science 78: 104127.

Siegel, S. (2011). 'The Contents of Perception'. In E. N. Zalta (ed.), The Stanford Encyclopedia of Philosophy. URL $=<$ http://plato.stanford.edu/archives/win2011/entries/perception-contents/>. Siegel, S. (2012). 'Cognitive penetrability and perceptual justification'. Nous 46: 201-222. 
Siegel, S. and N. Silins (2013). 'The epistemology of perception'. In M. Matthen (ed.), The Oxford Handbook on the Philosophy of Perception. Oxford: OUP (forthcoming).

Silins, N. (2008). 'Basic Justification and the Moorean Response to the Skeptic'. In T. S. Gendler and J. Hawthorne (eds), Oxford Studies in Epistemology Vol. 2. Oxford: OUP, pp. 108-141.

Tidman, P. (1994). 'Conceivability as a test for possibility'. American Philosophical Quarterly 31 : 297-309.

Vaidya, A. (2007). 'Epistemology of modality'. The Stanford Encyclopedia of Philosophy, Edward N. Zalta (ed.), URL $==<$ http://plato.stanford.edu/archives/sum2010/entries/modalityepistemology/>.

Van Fraassen, B. C. (1980). The scientific image. Oxford: OUP.

Van Inwagen, P. (2001). 'Modal Epistemology'. In his Ontology, Identity, and Modality. Essays in Metaphysics. Cambridge: Cambridge UP, pp. 243-258.

Vogel, J. (1990). Cartesian skepticism and inference to the best explanation. Journal of Philosophy, 87, $658-666$.

Vogel. J. (2004). 'Varieties of Skepticism'. Philosophy and Phenomenological Research 68: 1-37.

Vogel, J. (2005). 'The Refutation of Skepticism'. In M. Steup and E. Sosa (eds), Contemporary Debates in Epistemology. Malden, MA: Blackwell Publishing, pp. 72-84.

Weatherson, B. (2007). 'The Bayesian and the dogmatist'. Proceedings of the Aristotelian Society 107: $169-85$.

Weisberg, J. (2011). 'Varieties of Bayesianism'. In D. Gabbay, S. Hartmann and J. Woods (eds.), Handbook of the History of Logic, Vol. 10, pp. 477-551. Amsterdam: Elsevier/North-Holland. 
White, R. (2006). 'Problems of dogmatism'. Philosophical Studies 131: 525-557.

White, R. (2010). 'Evidential Symmetry and Mushy Credence'. In T. S. Gendler and J. Hawthorne (eds), Oxford Studies in Epistemology Vol. 3. Oxford: OUP, pp. 161-186.

Williamson, T. (2010). The Philosophy of Philosophy. Oxford: Blackwell.

Wright, C. (2002). ‘(Anti-)Sceptics Simple and Subtle: G. E. Moore and John McDowell’. Philosophy and Phenomenological Research, 65: 330-348.

Wright, C. (2004). 'Warrant for Nothing (and Foundations for Free?)'. Proceedings of the Aristotelian Society, Supplementary Volume 78: 167-212.

Yablo, S. (1993). 'Is Conceivability a Guide to Possibility?' Philosophy and Phenomenological Research 53: 1-42.

Yablo, S. (2002) 'Coulda, Woulda, Shoulda'. In T. S. Gendler and J. Hawthorne (Eds.) Conceivability and Possibility. Oxford: Clarendon Press, pp. 441-92.

Yalçin, Ü. (1992). 'Sceptical Arguments from Underdetermination'. Philosophical Studies 68: 1-34.

Ylikoski, P and J. Kuorikoski (2010) ‘Dissecting explanatory power’. Philosophical Studies 148: 201219. 